\title{
CORRECTION
}

\section{Correction to: Azo group(s) in selected macrocyclic compounds}

\author{
Ewa Wagner-Wysiecka ${ }^{1} \cdot$ Natalia Łukasik $^{1} \cdot$ Jan F. Biernat ${ }^{1} \cdot$ Elżbieta Luboch $^{1}$
}

Published online: 24 February 2018

(c) The Author(s) 2018. This article is an open access publication

\section{Correction to: \\ Journal of Inclusion Phenomena and Macrocyclic Chemistry \\ https://doi.org/10.1007/s10847-017-0779-4}

In the original publication of the article, a part of Scheme 12 was missed. The correct version of Scheme 12 was provided in this correction article. The original article has also been corrected.
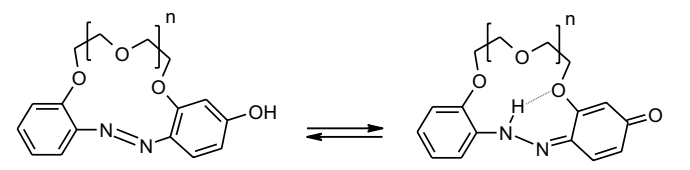

74. $n=1$
75. $n=2$

75. $n=2$

AZOPHENOL FORM
QUINONE-HYDRAZONE FORM

Scheme 12 Tautomeric equilibrium for hydroxyazobenzocrown ethers 74-76 showing hydrogen bond inside the cavity of quinonehydrazone form [158]
Open Access This article is distributed under the terms of the Creative Commons Attribution 4.0 International License (http://creativeco mmons.org/licenses/by/4.0/), which permits unrestricted use, distribution, and reproduction in any medium, provided you give appropriate credit to the original author(s) and the source, provide a link to the Creative Commons license, and indicate if changes were made.
The original article can be found online at https://doi.org/10.1007/ s10847-017-0779-4.

\section{Ewa Wagner-Wysiecka}

ewa.wagner-wysiecka@pg.edu.pl

$\triangle$ Elżbieta Luboch

elzbieta.luboch@pg.edu.pl

1 Department of Chemistry and Technology of Functional Materials, Faculty of Chemistry, Gdańsk University of Technology, Narutowicza Street 11/12, 80-233 Gdańsk, Poland 